\title{
Contexto
}

\section{Un análisis de la confianza en el sector público a través del elemento de la transparencia}

\author{
An Analysis of the Confidence in the Public Sector Through the Element \\ of Transparency \\ José Manuel Canales Aliende* \\ Adela Romero Tarín**
}

Invitados de honor

Resumen: es el Estado el universo en el que se concibe y desarrolla una sociedad, la cual establece un sistema de poder y un modelo económico capaces de asegurar deberes y derechos a todos sus integrantes. Con este postulado, y desde la óptica de la administración pública, es el gobierno el llamado a establecer principios y políticas de buen gobierno que garanticen la participación ciudadana a toda la sociedad civil, con transparencia, y a partir de principios universales como los derechos humanos, la meritocracia, la justicia y el orden constitucional, que son fruto de la cultura y de la idiosincrasia política de cada país en cada momento histórico.

Palabras clave: gobernanza, transparencia, sociedad civil, participación ciudadana, administración pública.

JEL: H83
Abstract: the government is the universe in which society has been conceived and developed, it has established a power system and economic model able to assure rights and responsibilities to all its members. From this perspective public management and the above postulate, government has to establish a proper policies of governance that guarantee participation to all civil society, in a transparent way and based upon universal principals, $v$ such as human rights, meritocracy, justice and constitutional order, which are the result of cultural and political process in each country at all times.

Keywords: Good governance, transparency, civil society, citizen participation, public administration.

* Ph.D. en Derecho, catedrático de Ciencia Política y de la Administración y Director del Observatorio Lucentino de Administración y Políticas Públicas Comparadas de la Universidad de Alicante, España. jm.canales@ua.es

** Ph.D. en Derecho, profesora de Ciencia Política y de la Administración de la Universidad de Alicante, España. adela.romero@ua.es 


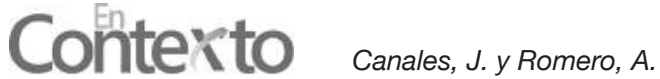

\section{Une analyse de la confiance dans le secteur public par le biais de l'élément de la transparence}

Résumé: c'est l'État, l'univers qui conçoit et développe une société qui établit un système de pouvoir et un modèle économique capables d'assurer les devoirs et droits à tous ses membres. De ce postulat, et dans l'optique de l'administration publique, c'est le gouvernement appelé à établir des principes et politiques de bon gouvernement de garantir la participation citoyenne à l'ensemble de la société civile, transparence et à partir de principes universels des droits de l'homme, méritocratie, la justice et l'ordre constitutionnel, qui sont le fruit de la culture et de l'particularismes politique de chaque pays à la maison moment historique.

Mots-clés: gouvernance, transparence, société civile, participation des citoyens, administration publique.

\section{Uma análise da confiança no sector público através do elemento de transparência}

Resumo: é o Estado, o universo em que concebe e desenvolve uma sociedade, que estabelece um sistema de poder e de um modelo económico capaz de garantir os direitos e os deveres de todos os seus membros. Com esta premissa e a partir da perspectiva da administração pública, é o governo chamado a estabelecer princípios e políticas da boa governação para assegurar a participação do cidadão para a sociedade civil, com transparência e com base em princípios universais como os direitos humanos, a meritocracia, da justiça e da ordem constitucional, que são o fruto da cultura e a idiossincrasia política de cada país em casa momento histórico.

Palavras-chave: governação, transparência, sociedade civil, participação do cidadão, administração pública. 


\section{Introducción}

La imbricación entre economía y sociedad, y entre éstas y la política, tiene una larga tradición doctrinal en las ciencias sociales, y constituye hoy un paradigma. El mundo actual es complejo y diverso en un contexto de globalización, y no puede, por tanto, analizarse sólo desde perspectivas y visiones unilaterales sino con base en explicaciones multivariables, y con plurales aportaciones disciplinares. Sin un análisis previo y reflexivo de la realidad es difícil poder afrontar la adopción de decisiones estratégicas y adecuadas, a la vez que fruto de éstas proceder a una adecuada, eficaz, transparente, y responsable actuación. El modelo existente del sistema político implicará un determinado modelo de Estado, de Gobierno y de Administración Pública.

Varias han sido las causas y los efectos de la situación de crisis estructural y múltiple en la que vive la sociedad hoy; y una manifestación de ella sería la crisis de los sistemas político-administrativos. A esta crisis de falta de legitimidad democrática, y de respuesta a los desafíos y problemas planteados, se pretende responder básicamente con lo que se ha denominado "Gobernanza" o "Buen Gobierno", frente a la precedente "desinstitucionalización democrática" o falta de calidad democrática, al fracaso en el desarrollo de la cultura, los valores públicos, y la capacidad de gobernar. El buen gobierno, por otro lado, es la antítesis y la prevención, y el remedio a la corrupción política y administrativa. Hay que señalar que el buen gobierno, entre otros principios y valores, sustancialmente implica lo siguiente:

- Transparencia y apertura "Open Government".

- Receptividad.

- Integridad ética.

- Vías de participación de sus empleados al interior, y de la ciudadanía al exterior.

- Rendición de cuentas, y exigencia de responsabilidades.

- Eficacia, eficiencia y economía.

- Accesibilidad física y documental a sus instituciones.

- Legalidad y calidad de las leyes aprobadas.

- Respeto y garantía de los derechos humanos.

- Resultados de la gestión.

- Emprendimiento y ecología.

El buen gobierno también equivalente al paradigma de la gobernanza e implica, además, sobrevalorar la relación dinámica y dialéctica del gobierno con la sociedad civil, superando visiones precedentes y obsoletas de contemplación 


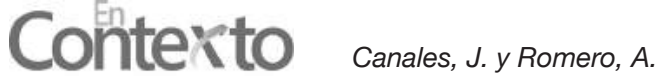

estática del gobierno. Este, a su vez, también se considera como un requisito imprescindible para el desarrollo económico.

\section{El paradigma de la gobernanza y sus principales características}

La Real Academia de la Lengua Española, en su sesión del 21 de diciembre de 2000, definió así la Gobernanza: “Arte o manera de gobernar que se propone como objetivo el logro de un desarrollo económico, social e institucional duradero, promoviendo un sano equilibrio entre el Estado, la sociedad, y el mercado de la economía".

De esta definición antedicha, se resalta lo siguiente:

- La gobernanza es, ante todo y sobre todo, un modo de gobernar; no es pues el único, y se deduce que es un novedoso modo de gobernar. Este modo de gobernar tendrá, por tanto, sus propias características diferenciadoras de otros.

- La gobernanza es un arte. Requiere pues un rodaje, una experimentación, un aprendizaje. No es una fórmula mágica o teoría completa, que dé la respuesta concreta. El carácter de arte hace que necesite desarrollarse hasta lograr resultados satisfactorios.

- El arte o modo de gobernar es un medio o instrumento para lograr un fin que sí es claro e inequívoco, aunque genérico y programático: "el logro de un desarrollo económico, social e institucional duradero".

- Ese fin del desarrollo no es único sino plural y complementario: "desarrollo económico, social e institucional", alejándose así de la concepción unidimensional neoliberal y economicista de la década de los sesenta y setenta, fruto del llamado "pensamiento único". Se hace hincapié, además, en el desarrollo social frente a los graves problemas sociales de hoy, y también en el desarrollo institucional, fruto de las aportaciones del "neo institucionalismo".

- Además el desarrollo, en sus varias facetas complementarias e integradas, debe ser no coyuntural o caprichoso sino duradero o permanente.

- El efecto o resultado de ese desarrollo producirá "un sano equilibrio", es decir: un justo, adecuado, e integrado equilibrio entre el Estado, la sociedad y el mercado.

- Es relevante señalar que la gobernanza supone, sobre todo, la superación de la dicotomía del dualismo entre Estado y sociedad civil, y de economía y sociedad; fruto de una concepción que tiene sus orígenes en el siglo XIX, con el nacimiento del Estado de Derecho. Esta es una nueva forma de relación y articulación entre el Estado, la sociedad, y el mercado de la economía. La relación es a tres, y no de dos en dos, o de forma separada. 
- En la definición de la Real Academia aparece La Sociedad, que se debe entender como sociedad civil; esta es la nueva protagonista en la relación, que tiene y que va a reclamar su papel, básicamente a través de la participación ciudadana o participación de sus miembros. Esa mención expresa de la sociedad es lo que conlleva a plantear, implícitamente, que toda gobernanza debe ser democrática por esencia.

Existe una correlación importante, a su vez, entre gobernanza y sociedad civil, siendo ambas fruto y exposición simultánea de la realidad de cada contexto histórico y geopolítico. El concepto de sociedad civil, a su vez, es polisémico y expresa la articulación de las distintas redes, asociaciones y movimientos sociales. De manera que cuando la sociedad civil sea más relevante más papel jugará en cada sistema político analizado.

Hay que señalar que el Buen Gobierno es un medio para lograr el fin de la democracia plena, auténtica, de calidad o fortalecida; y también a la vez "la felicidad" de la sociedad civil y de la ciudadanía. La calidad de la democracia, es más que el ejercicio temporal del voto y que la legitimación representativa de los partidos. Un principio y un factor relevante de la manifestación del bueno gobierno, entre los varios antes señalados, es sin duda el de la participación ciudadana que busca nuevas fórmulas, además de las clásicas a las que considera insuficientes.

La democracia participativa y la deliberativa complementan y amplían la democracia representativa clásica. El capital social es un elemento o factor cuantitativo y cualitativo que manifiesta la calidad de la democracia y debe haber una coherencia entre capital social expresivo de la sociedad, y de ésta con la democracia, determinando el grado e intensidad de la articulación social y de la participación ciudadana.

\section{Discusión}

En un análisis sociopolítico integral actual de una sociedad y un sistema sociopolítico deben contemplarse, además del capital físico (territorio e infraestructuras básicamente), y del capital o talento humano (clave para la sanidad actual del conocimiento), también el capital social. La corrupción política y administrativa no son nuevas en la humanidad, hoy se manifiestan de formas diversas, y constituyen la amenaza y el azote del buen gobierno, y por ende de la calidad de la democracia. Esta a su vez produce una desafección progresiva de los ciudadanos hacia las instituciones públicas a las que deslegitiman, y a un alejamiento crítico de la clase política, lo cual implica la debilidad de las instituciones y de los valores públicos de la sociedad. 


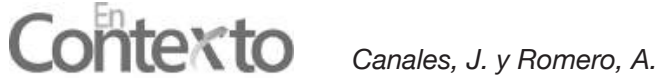

Si bien siempre ha existido la corrupción, hoy es más demandada por la ciudadanía no sólo su mayor prevención sino, sobre todo, la mayor exigencia de responsabilidades. Ahora bien, la corrupción no sólo tiene costes políticos y sociales sino también económicos, pues afecta el funcionamiento normal de la Hacienda Pública de cualquier país, y hace que se produzca un incremento del fraude fiscal y del gasto público innecesarios. Por otro lado, no basta sólo con la lucha y represión de la corrupción en sus varias facetas sino que es fundamental su prevención, básicamente a través de la educación y la cultura cívicas democráticas ligadas a la ética pública.

Hay sectores administrativos prioritarios en la prevención y lucha contra la corrupción, como los siguientes: a) el urbanismo; b) la contratación pública; c) la financiación de los partidos políticos y asociaciones de diverso tipo; d) las subvenciones a la cooperación internacional. Como parte de las medidas adoptadas para el buen gobierno en algunos países, se han puesto en marcha proyectos de gobierno y de gestión pública en red, y de "Gobierno Abierto" ("Open Governement"), y, en particular, podría citarse el memorándum del Gobierno del Presidente Obama, de enero de 2009, sobre transparencia y gobierno abierto, basado en tres pilares básicos: a) transparencia, b) colaboración, y c) participación.

Ahora bien, el Buen Gobierno como ha puesto de relieve el neoinstitucionalismo, requiere: a) un cambio organizativo profundo, b) un cambio en la cultura política, c) un liderazgo adecuado al medio, d) una potenciación de la participación ciudadana para hacer realidad el capital social. Al respecto, a nivel europeo podrían citarse como documentos básicos de interés, los siguientes: El Libro Blanco de la Gobernanza Europea, aprobado en 2001 por la Comisión Europeay que constituye un auténtico código normativo y programático para todas las instituciones y países miembros de la Unión Europea:

- La propuesta del Grupo de Derecho Administrativo del Consejo de Europa, que ha desarrollado también "Treinta y tres principios del Buen Gobierno", que es también un auténtico código de buen gobierno, y que contiene una síntesis y mezcla heterogénea de distintos principios, valores y reglas de actuación, comunes a todos los países miembros y que están aprobados en la mayoría de los ordenamientos jurídicos de los países miembros.

- El proyecto "non nato" de Constitución de la Unión Europea, contiene también una serie de principios del Buen Gobierno y de la Buena Administración Pública. 
El republicanismo o humanismo cívico es una corriente de pensamiento actual, inspirada en la historia de Roma, en la que se ensalzaban los valores de la "res publica", la "civitas" y las virtudes cívicas, que pretende legitimar y fortalecer el papel de lo público, de sus valores y de las instituciones de este carácter, frente a los duros y frontales ataques sufridos por el neoliberalismo surgido tras la crisis del petróleo en 1973, y luego expandido por todo el mundo. El neoliberalismo se caracteriza sustancialmente, como es sabido, por principios del individualismo, conductismo, consumismo y capitalismo salvaje. Este neoliberalismo, en el contexto actual de la globalización, y sobre todo por su carácter incontrolado, han supuesto un debilitamiento progresivo de todo lo público; no obstante, en la historia ha habido múltiples pensadores preocupados por el buen gobierno.

El republicanismo cívico y sus distintas modalidades, sería hoy una de las ideologías básicas explicativas y legitimadoras del llamado buen gobierno o gobernanza democrática, expresión que es, ante todo y sobre todo, una "ideafuerza" que pretende convertirse en una realidad viva. Una manifestación y efecto del buen gobierno, entendido éste en sentido amplio, es la buena administración, que implica una plena vigorización y modernización de la misma, con visión estratégica, e impregnada de valores públicos democráticos. Sin perjuicio de que numerosas instituciones públicas y privadas han seleccionado y propuesto indicadores para la medición de la transparencia y del buen gobierno, y de que éstos puedan ser útiles y orientativos, la transparencia y el buen gobierno son aspectos básicamente cualitativos, y son fruto de la cultura y de la idiosincrasia política de cada país en cada momento histórico.

Las administraciones públicas contemporáneas están llamadas, hoy más que nunca, a satisfacer las demandas de la ciudadanía y de la sociedad civil, legitimando su acción siempre en la búsqueda del interés general. Esto a través de políticas públicas adecuadas a esas finalidades y con la praxis de una gestión pública inspirada también en los valores y los principios orientadores antedichos del buen gobierno. Estos a su vez, aprobarán y aplicarán diversas medidas técnicas e instrumentos para llevarlo a cabo del mejor y más eficaz modo, a saber: a) código de ética administrativa, b) cartas de servicios, c) implantación de la filosofía y técnicas de la planificación estratégica y evaluación, entre otros.

Ahora bien, la gestión pública actual, sin perjuicio de su titularidad pública, no excluye la participación del llamado "tercer sector" o de las empresas para la colaboración mutua. El partenariado y los consorcios aparecen como nuevas y útiles fórmulas organizativas de actuación público-privada. Dentro de la administración pública un aspecto relevante y estratégico a considerar 


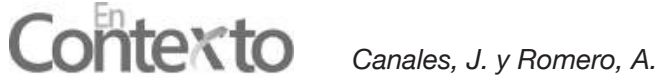

es el papel de los empleados públicos o el "servicio civil de carrera"; el profesionalismo, la honestidad, y la independencia de éstos constituyen un requisito previo e imprescindible para una gestión pública moderna, eficaz y con calidad democrática.

Hay que señalar que existen apartados con diversos ámbitos territoriales de aplicación (Estados, gobiernos locales, entre otros), numerosos códigos del llamado "Buen Gobierno", y entre ellos se destaca: el Código Iberoamericano de Buen Gobierno, aprobado en Montevideo (Uruguay) el 23 de junio de 2006. Estos códigos son ciertamente útiles en principio, pero plantean el problema de su falta de coercitividad, y pueden llegar a convertirse en "papel mojado", y, por lo tanto, inútiles por su inaplicabilidad y por la ausencia de responsabilidad exigible. Por último, habría que señalar también que el buen gobierno debe ser estratégico, y no cortoplacista, pues el logro de políticas públicas satisfactorias para la ciudadanía no es ni fácil ni se resuelve en pocos días.

\section{Conclusiones}

El logro de la calidad democrática, una de cuyas manifestaciones sería el buen gobierno, requiere un marco conceptual e institucional más amplio, ya que debe contemplarse dentro de la realidad de cada sistema político-administrativo. En el sentido antedicho, no bastarán sólo el conjunto de medidas que se incluyen dentro del llamado buen gobierno sino que también se deberán acompañar y completar con una transformación de la configuración y actuación de los principales actores e instituciones políticas de carácter decisorio y representativo. En particular, se destacaría la variable esencial, aunque no única, de la importancia de la democracia interna, de la transparencia de los partidos políticos, y de la capacitación meritocrática y ordenada de las élites políticas, para que en su sistema político administrativo pueda lograrse eficazmente el buen gobierno.

Además de lo anterior es obvio que el marco conceptual y el contenido del Estado de Derecho debería reforzarse más, y hacerse plenamente democrático. No bastan Estados de Derecho formales y simbólicos sin que éstos lo sean de verdad en su praxis. En particular resulta relevante, dentro de esta institucionalización y consolidación del Estado de Derecho, frente a su debilidad, priorizar los siguientes aspectos, de forma clara e inequívoca:

- Una clara separación de poderes del Estado.

- Preminencia del parlamento como expresión de la soberanía popular frente al presidencialismo irresponsable y sin control.

- La aprobación y vigencia de una legislación reguladora de los partidos políticos. 
- La eficacia y la garantía plena de los Derechos Humanos.

- Una legislación penal contra los delitos de corrupción.

- Una administración de justicia independiente, profesional y rápida.

- Una legislación reguladora de los lobistas y de los grupos de presión.

- Una legislación protectora y garante de la interinidad personal.

- La aprobación y puesta en marcha de nuevas vías de participación democrática de los ciudadanos y de la sociedad civil.

- Una educación escolar que transmita conocimientos y valores cívicos.

- El establecimiento de un "servicio civil de carrera" profesional y meritocrático.

\section{Referencias}

Ackerman, J. (Ed.). (2008). Más allá del acceso a la información: transparencia, rendición de cuentas y Estado de Derecho. Ciudad de México, México: Siglo XXI.

Ackerman, R. (2001). La corrupción y los gobiernos. Madrid, España: Siglo XXI.

Beck, U. (2002). La sociedad del riesgo global. Madrid, España: Siglo XXI.

Bergerven, N. y Gardels, N. (2012). Gobernanza Inteligente para el siglo XXI. Una vía intermedia entre Occidente y Oriente. Madrid, España: Santillana.

Bobbio, N. (2000). El futuro de la democracia. Ciudad de México, México: Fondo de Cultura Económica.

Boin, A., Hart, P., Stern, E., Sundelius, B. (2007). La política de la gestión de la crisis. El liderazgo político bajo presión. Madrid, España: INAP.

Camps, V. (2010). La democracia sin ciudadanos. La construcción de la ciudadanía en las democracias liberales. Madrid, España: Trotta.

Canales, J. (2002). Lecciones de Administración y de Gestión Pública. Alicante, España: Servicio de Publicaciones de la Universidad de Alicante.

Canales, J. (2009). Documentos Básicos para la Modernización y el Fortalecimiento de las Administraciones Públicas en Iberoamérica. Alicante, España: Editorial Club Universitario.

Carrillo, F. y Cordero, L. (Ed.). (2007). Hacia el Buen Gobierno. Tareas aún pendientes. San José de Costa Rica, Costa Rica: Fundación Arias para la Paz y el Progreso.

Cotarelo, R. y Crespo, I. (2012). La comunicación política y las nuevas tecnologías. Madrid, España: La Catarata. 


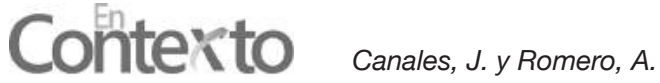

Crozier, M. (1992). Estado Moderno. Estado Modesto. Estrategia para el cambio. Ciudad de México, México: Fondo de Cultura Económica.

Dahl, R. (1999). La democracia. Una guía para los ciudadanos. Madrid, España: Taurus.

Donolo, C. (1999). ¿Cómo gobernar mañana? Barcelona, España: Galaxia Gutenberg y Círculo de Lectores.

Dror, Y. (1994). La capacidad para gobernar. Informe al Club de Roma. Barcelona, España: Editorial Galaxia Gutenberg y Círculo de Lectores.

Fernández-Albertos, J. (2012). Democracia Intervenida. Políticas Económicas en la Gran Depresión. Madrid, España: Catarata y Fundación Alternativas.

Ferraro, A. (Ed.). (2007). En busca del buen gobierno. Nuevas perspectivas sobre política y gestión del Estado en América Latina. Barcelona, España: Bellaterra.

De Francisco, A. (2007). Ciudadanía y democracia. Un enfoque republicano. Madrid, España: Catarata.

García, M. (1986). El Estado de Partidos. Madrid, España: Alianza.

Giner, S. y Sarasa, S. (Ed.). (1997). Buen Gobierno y política social. Barcelona, España: Ariel.

Gracian, B. (1993). El Arte de la Prudencia. Madrid, España: Temas de Hoy.

Hechlo, H. (2008). Pensar institucionalmente. Barcelona, España: Paidós.

Held, D. (2010). Cosmopolitismo: Ideales y Realidades. Madrid, España:Alianza.

Hermet, G. (2008). El invierno de la democracia. Auge y decadencia del gobierno del pueblo. Barcelona, España: del Lince.

Innerarity, D. (2011). La democracia del conocimiento. Por una sociedad inteligente. Barcelona, España: Paidós.

Kunt, H. (2000). Reivindicación de una ética mundial. Madrid, España: Trotta.

Lamo, E. (9 de junio de 2013). Sociedad Civil y Regeneración Democrática. $A B C$. Recuperado de https://www.ucm.es/data/cont/media/www/pag18556/op.\%20abc.pdf

López, J. (1868). Ética y Politica. Madrid, España: Guadarrama.

Maravall, J. (2013). Las promesas políticas. Barcelona, España: Galaxia Gutenberg.

March, J. y Olsen, J. (1997). El redescubrimiento de las instituciones. La Base Organizativa de la Política. Ciudad de México, México: Fondo de Cultura Económica. 
Martínez, A. (2006). Representación y Calidad de la Democracia en España. Madrid, España: Tecnos.

Martínez, M. y Mella, M. (2012). Partidos políticos y sistemas de partidos. Madrid, España: Trotta.

Montero, J. y Torcal, M. (14 de junio de 2013). No es descontento, es la desafección. El País. p.31.

Natera, A. (2001). El liderazgo político en la sociedad democrática. Madrid, España: Centro de Estudios Constitucionales.

North, D. (1993). Instituciones, Cambio Institucional y Desempeño económico. Ciudad de México, México: Fondo de Cultura Económica.

OCDE. (2003). El gobierno del futuro. Recuperado de http://www. oecdbookshop.org/get-it.php?REF=5LMQCR2JDXQ7\&TYPE=browse

Pérez, V. (1997). La esfera pública y la sociedad civil. Madrid, España: Taurus.

Peters, G. (2003). El nuevo institucionalismo. Teoría institucional en ciencia política. Barcelona, España. Editorial Gedisa.

Powell, N. y Dimaggio, P. (Ed.). El nuevo institucionalismo en el análisis organizacional. Ciudad de México, México. Fondo de Cultura Económico.

Putnam, R. (1993). Making Democracy Work. Civic tradicions in Modern Italy. New Jersey, U.S.A.: Princeton University Press.

Ramos, C. (2013). Democracia Hacker. El poder de los ciudadanos. Granada, España: Algón.

Rosanvallon, P. (2010). La legitimidad democrática. Barcelona, España: Paidós.

Rothkops, D. (2008). El Club de los elegidos. Cómo la élite del poder global gobierna el mundo. Barcelona, España: Urano.

Rovira, A. (Ed.). (2003). Gobernanza Democrática. Madrid, España: Marcial Pons.

Sartori, G. (2001). La sociedad multiétnica. Pluralismo, multiculturalismo y extranjeros. Madrid, España: Taurus.

Sosa, F. y Fuertes, M. (2011). La Bancarrota del Estado y Europa como contexto. Madrid, España: Marcial Pons.

Tamames, R. (2012). La crisis de la deuda soberana en la eurozona: España, un proyecto de pais. Madrid, España: Turpial.

Tria, G. y Volotti, G. (Ed.). (2013). Reforming the Public Sector. How to Achieve Better Trasparency, Service and Leadership. Virginia, U.S.A.: R.R. Donnelley. 


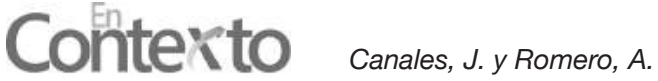

Tourain, A. (2011). Después de la crisis. Por un futuro sin marginación. Madrid, España: Taurus.

V. V. A. A. (2010). Calidad Democrática y Buen Gobierno. Madrid, España: Federación Española de Municipios y Provincias.

Villoria, M. (2011). ¿Más libertad o más felicidad? El Buen Gobierno del siglo XXI. Reforma y Democracia. 51, 7-44.

Von, K. (1996). Teoría Política del Siglo XXI. De la modernidad a la postmodernidad. Madrid, España: Alianza.

\section{Para citar este artículo:}

Canales, J. y Romero, A. (2016). Un análisis de la confianza en el sector público a través del elemento de la transparencia. En-Contexto, 4(4), 63-74. 